\title{
ECONOMIC LOAD DISPATCH PROBLEMS IN SMART GRID: A REVIEW
}

\author{
Ms. Frie Ayalew \\ Department of Electrical and \\ Computer Engineering \\ Addis Ababa Science and \\ Technology University \\ Addis Ababa, Ethiopia
}

\author{
Ms. Seada Hussen \\ Department of Electrical and \\ Computer Engineering \\ Addis Ababa Science and \\ Technology University \\ Addis Ababa, Ethiopia
}

\author{
Dr. Gopi Krishna Pasam \\ Department of Electrical and \\ Computer Engineering \\ Addis Ababa Science and \\ Technology University \\ Addis Ababa, Ethiopia
}

\begin{abstract}
$A B S T R A C T$ - Economic dispatch problem is one of the fundamental problems in power system as proved by many researchers. Since working on smart grid at lowest cost with high efficiency is a big challenge. Solving this problem will be active research topic for future. In the current paper, we are going to show detailed description of progress on economic dispatch, centralized and decentralized algorithm, and demand side management, classical and modern techniques by looking for the way and key factors in their progress. Plenty of work is available on demand side management, using different alternatives as it is related to optimization of generation, and system load cost models. With this scope of review work, the perspective of the economic dispatch problem in the smart grid has been investigated. This paper revises different author's work related to the economic dispatch problem and gives an insight to future work.
\end{abstract}

Keywords: Centralized algorithm, Distributed algorithm, Demand response, Demand side management, Economic dispatch, Unit commitment, Smart grid

\section{INTRODUCTION}

The main aim of today's electrical utility is to provide electrical power in a reliable way and in a possible low cost. Electrical energy cannot be stored, but it can be generated from available sources be it conventional resources or renewable energy sources. In Q. Xu. et al (2013)Matlab is used to implement real time generation dispatch and communication architecture of smart grid with renewable energy. In Yang, Z .et al (2014) non-convex nonlinear dispatch problem was solved by self-leaning teaching learning based optimization. Sailaja. et al (2017)have presented artificial neural network and fuzzy systems in smart grid using distributed energy storage systems for solving unit commitment problem.

In L. I. Dulau.et al (2017) economic dispatch approach in smart grid without considering network equality security constrained by testing three generator and one battery storage to minimize total power generation cost. In N. Nikmehr. et al (2015) determined optimal economic generation of each micro grid (MGs) by using stochastic and probabilistic modeling for both small scale energy resources and load demand at each micro grids since particle swarm optimization techniques was used to optimize cost function, In K. Gnanambal. et al (2016)have proposed quasi-oppositional particle swarm optimization by considering network loss and security constrained to control system losses, fuel consumption and control movement of generator output. H.Sita. et al (2016)summarized recent trends in economic dispatch problem.

In N. Ghorbani. et al (2016) use a method of solving multi-objective optimization problems by using per unit coding for converting multi-objective functions to a single objective model. Kaima. et al (2017) had been proposed economic dispatch strategy with the consideration of demand response to keep the electricity real time balance. In $\mathrm{M}$. Nassourou.et al (2017) economic model predictive control was applied in smart micogrid system connected to an electric power grid and compares several subsystems.

In V. Bhattachajee. et al (2017) introduce a convex nonlinear cost saving model for optimal economic dispatch problem in smart micro grid and combined storage degradation cost and intermittent renewable energy generation without considering the effect of variation of temperature on the charging and discharging a battery efficiency. In S. Surender Reddy (2017) combined environmental and economic dispatch problem has solved by using multi objective based adaptive immune algorithm. In $\mathbf{M}$ .Uassouvoll, etal (2017) applied robust optimization on economic dispatch problem of smart grid to minimize cost and guarantee service of reliability. F. Fioretto .et al (2017) introduce an effective multi objective algorithm and distributed constrained optimization approach was done with demand responses to maximize th benefits of customers and 


\section{International Journal of Engineering Applied Sciences and Technology, 2019 \\ Vol. 3, Issue 11, ISSN No. 2455-2143, Pages 71-77 \\ Published Online March 2019 in IJEAST (http://www.ijeast.com)}

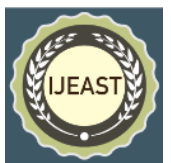

minimizes generation cost. In Shahid, H.et al (2018) Genetic algorithm (GA) was implemented to model ELD problem for solar power plants synchronized with thermal power plants.

\section{MOTIVATION OF THE REVIEW}

The issue of continually increasing demand and price of electricity at the consumer end inspire the review presented. For a better knowledge how we have to reduce the price by searching and knowing of economic dispatch problems for smart technologies.

\section{OBJECTIVE OF THE REVIEW}

The objective of the review is to discuss in detail about the various smart grid components, their continuous development, technical challenges faced during their development, outcomes achieved and ways to reduce the price of electricity with related to smart grid.

\section{OVERVIEW OF ECONOMIC DISPATCH PROBLEM ON SMART GRID}

Economic dispatch is a short term determination of optimal output of number of electricity generation facilities, to meet the system load at the lowest possible cost subject to transmission and operational constrained [6]. But it's one of the fundamental problems in power system. Its objective is to minimize the total power generation cost. And it can be done by considering transmission loss or without considering transmission loss [24].

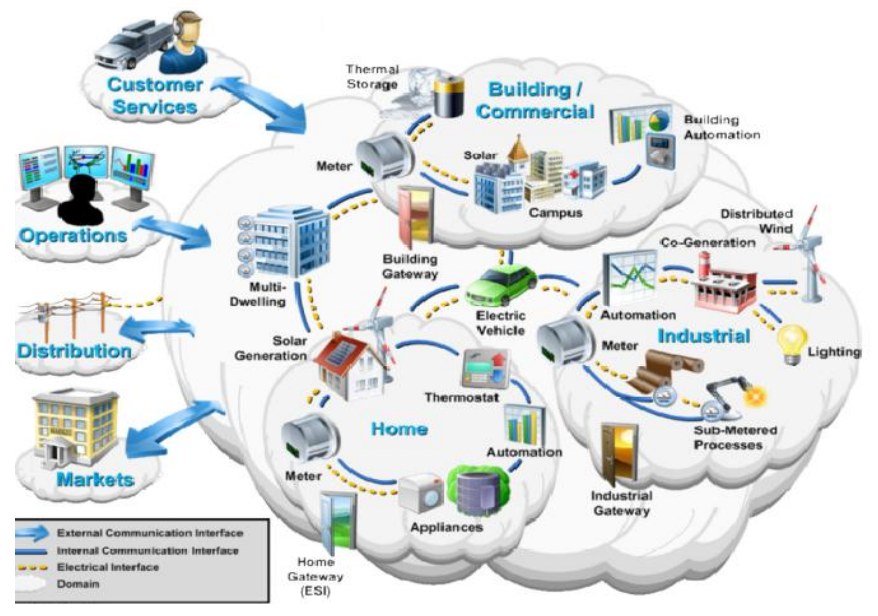

Fig 1: Overview smart grid [24]

\section{COST REDUCTION METHODS IN SMART GRID}

Reduction of different costs includes reduction of energy or production cost which are (fuel cost and operation and maintenance cost), timing of additional units which is (plant cost), and environmental costs which are (NOx, COx, SOx emissions). In addition to this, by using energy sources, direct algorithms and demand managements, we can reduce the cost of the systems [36].

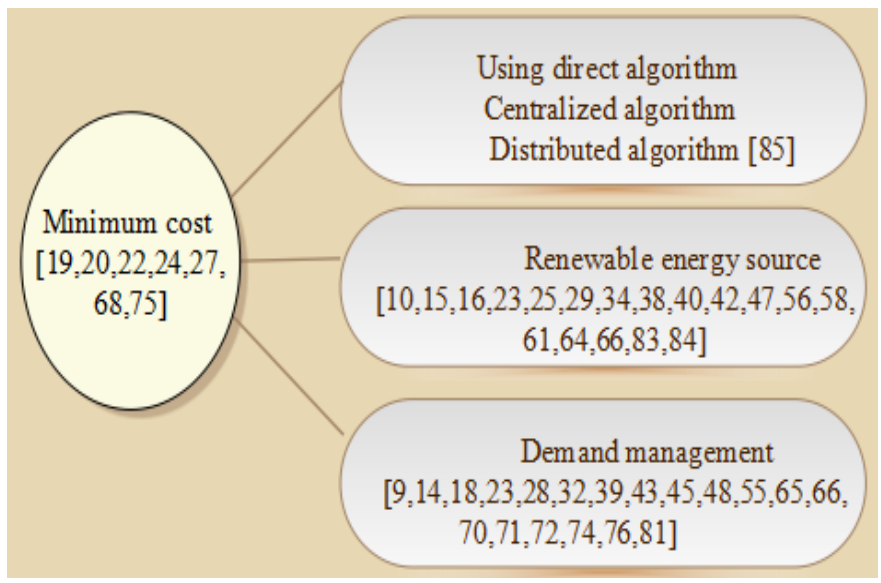

Fig 2: Different methods of cost reduction techniques

\section{A. Energy source}

Based on energy source some of author's doing their paper for minimization of cost either conventional energy, renewable energy, electric vehicle or fuel as a source. Distributed generation encompasses a wide range of technologies including solar power, wind turbines, fuel cells, micro turbines, reciprocating engines, load reduction technologies, and battery storage systems. Among all alternatives, solar and wind energy sources produce intermittent power and other technologies may need to be shut down for periodic maintenance [6].

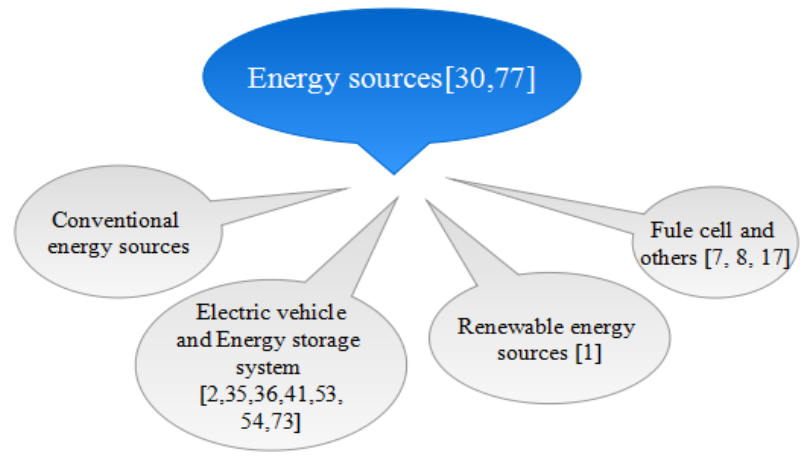

Fig 3: Energy source used in smart grid

\section{B. Conventional and modern methods}

Economic dispatch problem had been achieved by using centralized and decentralized approaches. Economic dispatch problem solved by many traditional methods or by using 


\section{International Journal of Engineering Applied Sciences and Technology, 2019 \\ Vol. 3, Issue 11, ISSN No. 2455-2143, Pages 71-77 \\ Published Online March 2019 in IJEAST (http://www.ijeast.com)}

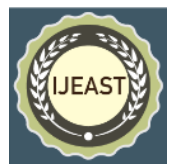

conventional methods that are used in the centralized algorithm has difficulty on local minima [11]. Centralized or conventional economic dispatch algorithm methods are Lagrangian, Lambda iteration, quadratic equation and so on. Those approaches are estimates or statistics of power generation and loads, acquired by a central controller are accurate [21]. The distributed one or modern methods are use artificial intelligent techniques like fussy logic, particle swarm optimization, and genetic algorithm.
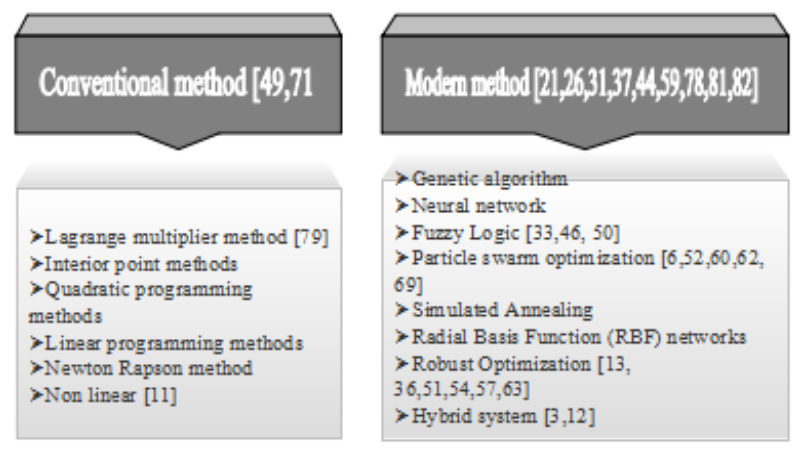

Fig 4: conventional and modern techiniques list.

\section{Benefits and Challenges of modern and conventional methods}

Most the papers used the distributed algorithm techniques among the reference some author is compared the results of conventional techniques with modern one [36]. Conventional technique compared with modern one has its own limitations and advantages such as its old or traditional methods, less cost and uses more time for responses. It uses iterations, this lose more time and the modern (distributive methods) is high cost, used for smart grid and uses simple algorithm.

\section{Energy managements}

Energy managements is one of the method for reduction of cost in power systems. It includes generation planning and management, utility management, demand side management and smart metering.

- Utility management: - under utility management, we are looking their work as load research, load shape objective, program implementation strategy, implementation, monitoring and evaluation [21 - 23].

$>$ Generation planning and management:-load forecasting, generation planning, generation costing, financial analysis, price allocation is included under this [23].

Demand side management:- demand response program, smart metering, distributed generation under this small scale renewable generation, battery energy storage system, electric vehicles, Distribution generation DG sets, fuel cells are included $[9,14,18,23,28,32,39,43,45$, $48,55,65,66,70,71,72,74,76,81]$

$>$ Smart metering: - smart metering and monitoring and security and privacy [27].

\section{Benefit of economic load dispatch problems on smart grid}

Integration of electrical and information infrastructures and incorporation of automation and information technologies with our existing electrical network need comprehensive solutions such as:

> Improve distribution power system reliability, operational performance and overall productivity.

$>$ Increases energy efficiency and decreases carbon emissions.

$>$ By empowering the consumers manage their energy usage and save money without compromising their lifestyle.

> Optimize renewable energy integration and enabling broader penetration

$>$ Delivers meaningful, measurable and sustainable benefits to the utility, the consumer, the economy and the environment $[5,17]$.

Advantages of smart grid over old grid [24]

\section{Smart grid}

$>$ If the power outage is happening it restores automatically

$>\quad$ When demand is peak the utility suppresses

$>$ Less cost

$>$ It is working with higher wind and solar penetration

$>\quad$ It can manage distributed generation safely

$>$ Reduce emissions, customer bill, and $2 \%$ power loss

Old grid

$>\quad$ When demand is peak utility pays

$>$ Management high wind and solar penetration is difficult

$>$ Cannot manage distributed generation safely

$>$ Has $10 \%$ power loss in transmission \& distribution systems

\section{OBSERVATIONS}

$>$ Genetic algorithm have no guaranteed to be optimum for optimal power flow solution, execution time and quality of the solution, deteriorate with the increase of the chromosome length. It's execution time could be a disadvantage of GA, if the number of generators increases [19].

$>$ For lowest energy consumption, and successful control of energy dispatch in smart micro-grids EMPC (economic model predictive control) yields a better economic result and it is preferable [13][10]. 
$>$ The better solution of cost minimization and efficiency improvement of the smart grid is installing of renewable energy sources [1].

$>$ Negotiation problem between the generation company and multiple utility companies are bargaining problem [18].

\section{CONCLUSION AND RECOMMENDATION}

\section{A. Conclusion}

Economic dispatch and unit commitment are essential problems to be solved in order to supply highquality electric power to customers. Smart grid is used to improve economic dispatch and unit commitment problems. A smart grid is generally economic, reliable, secure, efficient and environmental friendly systems. Since, in smart grid interconnected elements from central and distributed generator up to end user is monitored, protected and automatically optimized. To reduce cost and getting efficient power many researcher proposed different methods by using high penetration of renewable energy sources, the large amount of energy that can be stored and different methods used in economic dispatch algorithm that are conventional and modern techniques, use energy management techniques like smart metering, demand side management, vehicle to grid connection and soon. This paper reviewed several papers related to economic dispatch problem, show used method, overview of smart grid, comparison between central and distributed algorithm and smart and old grid, observing the best method among them, and recommend some indication for future works.

\section{B. Recommendation}

Distributed optimization algorithms are recommended for solving non-linear optimization problems with low latency and higher accuracy.

$>$ Focus on studying effect of temperature variations on semi-empirical models of available capacity of the storage unit and designing faster distributed techniques for improving upon the convergence rates of the system.

$>$ How to develop a distribute economic dispatch strategy based on stochastic programming method is an interesting topic worthy of consideration as a future work

$>$ Scalability and on computing solutions using an iterative process to refine the level of discretization for the generators and load outputs.

$>$ Genetic algorithm method is recommended because, it can use in both integer and discrete variables, it can globally optimum solution as it can avoid the trap of local optima and deal with the non-smooth, noncontinuous, non-convex and non-differentiable functions which actually exist in practical optimization problems.

$>$ Construction of a real intelligent communication network with high-speed two-way functions has been recommended.

$>$ For solving of economic dispatch problem as well as optimal sizing of batteries banks Metaheuristic algorithm is recommended.

\section{REFERENCES}

[1] Qiushi.Xu, Changhong Deng, and Leichen(2013). Real time generation dispatch and communication Architecture of smart grid with Renewable energy, China, 14018, No 8.

[2] Yang, Z., Li, K., Niu, Q., Xue, Y., \& Foley, A. (2014). A self-learning teaching-learning based optimization for dynamic economic/environmental dispatch considering multiple plug-in electric vehicle loads. Journal of Modern Power Systems and Clean Energy , 2(4), 298307. DOI: 10.1007/s40565-014-0087-6.

[3] C.Sailaja , R.Sadhasivam(2014). A Solution of Short Term Unit Commitment in Smart Grid Using Artificial Neural Network and Fuzzy Logic, e-ISSN: 2278-1676,pISSN: 2320-3331, Volume 9, Issue 2 Ver. II (Mar - Apr. 2014), PP 01-05.

[4] Lucian Ioan Dulau, Mihail Abrudean, Donin Bica(2015). Smart grid economic dispatch, 8-9, Romania.

[5] N.Nikmehr,S.N.Ravadanegh(2015). Optimal power dispatch of multi micro grids at future smart distribution grids, In IEEE Transaction smart grid.

[6] Dr. K. Gnanambal , A. Marimuthu, K. Jeyanthi(2016). Two Stage Approach for Economic Dispatch in Using Quasi-Oppositional Based Particle Swarm Optimization" International Conference on Innovations in Engineering and Technology (ICIET), e-ISSN: 24555703 .

[7] H.Sita, Dr. P. U. Reddy(2016). A Comprehensive Study On Combined Economic and Emission Dispatch Optimization Problem, e-ISSN: 2278-1676,p-ISSN: 2320-3331, PP 01-09.

[8] N. Ghorbani, E. Babaei. S.Looli, P.Farhadi(2016). Per unit coding for combined economic emission load dispatch using smart algorithm, Vol 5, No 2, PP.11:21.

[9] Kaima, congshan wang, Jie yang, Qiuxia yang and Yazhou yuan,(2017). Economic dispatch with demand Response in Smart Grid, 12.

[10] M. Nassourou, V. Puig, J. Blesa, C.Ocampomartinez(2017). Economic model predictive control for Energy Dispatch of a smart micro grid system, Career Llorens Artigas, 4-6, 08028, Barcelona(Spain). 
[11] Vikraw Bhattachajee, Irfan Khan(2017). A non-Linear convex cost model for economic dispatch in micro grids, Carnegie Mellon university, Pittsburgh PA, USA..

[12] S. Surender Reddy(2017). Multi-objective based Adaptive Immune Algorithm for solving the economic and environmental dispatch problem, ISSN 0973-4562, Volume 12, Nov 6, pp. 1043-1048, Korea.

[13] M .Uassouvoll, etal. (2017). Robust optimization based energy dispatch in smart grids considering demand uncertainty, J, phys; conf, ser, 783012033.

[14] F. Fioretto,W. Yeoha, Enrico. P,Ye Ma ,Satishkumar J.R.(2017). A Distributed Constraint Optimization (DCOP) Approach to the Economic Dispatch with Demand Response, USA.

[15] Shahid, H., Aslam, Z. and Mahmood, Z(2018). Optimization of Economic Load Dispatch for 2.5 MW Solar Power System, European Journal of Sustainable Development Research, 2(3),27.

[16] Fanghong Duho, Changyunwen(2015). Distributed economic dispatch smart grids with Random wind power, IEEE.

[17] WenxiaLiu, YuyingZhang, BoZeng, ShuyaNiu, JianhuaZhang, and YongXiao(2014). An EnvironmentalEconomic Dispatch Method for Smart Microgrids Using VSS_QGA, Hindawi Publishing Corporation Journal of Applied Mathematics Volume 2014, Article ID 623216, 11 pages http://dx.doi.org/10.1155/2014/623216,2014.

[18] Kaima, congshan wang, Jie yang, Qiuxia yang and Yazhou yuan(2017), Economic dispatch with demand Response in Smart Grid, 12 AUG 2017.

[19] Juon Pallo Fossati(2012). Unit commitment and economic dispatch in micro grid.

[20] Avikarsha Mandal, Erik Zenner, Poster(2012). Privacy in Distributed Economic Dispatch in Smart Grid, Offenburg University of Applied Sciences Offenburg, Germany.

[21] Hae Liang, Bong Junchoi, Atof Abdirable, Weihua zhuang, and Xuemin(2017). Decentralize Economic dispatch in micro grid Via Heterogeneous Wireless Networks, IEEE Journal, Vol, XX, No, XX.

[22] R. Mudumbai and S. Dasgupta(2013). Distributed control for the smart grid, Iowa city IA 52242.

[23] Kjarapu, Sathish Kumas, Snim Ebraheam(2015). Integration of demand response and distributed generation for economic load dispatch problem, Vol 4, Issua 2.

[24] Jon D. Mc Donald, P.E(2002). Smart grid application standards development and Recent developments, 31/10, 054.

[25] A.C.Luna, N.L.Diaz, Andrade, Moises Gaells, M. Guerrero and S.C.Vasquez. (2015). Economic power dispatch of distributed generators in a grid connected micro grid, In Proc. ECCE-ASIA.
[26] D.k. Thesia, P. Jangir, Dr. I. N. Tnivedi,(2015). Economic Emission Dispatch problem solutions using Anti-colony optimization of micro-grid in Island mode, Volume 2,Issuse.

[27] D.Sankar Roy, Venkataswamy(2015). optimization in economic load dispatch with security constraints, international journal of current engineering and scientific research (ijcesr), issn (print): 2393-8374, (online): 2394-0697, volume-2, issue-3.

[28] Xin Lou, Rui Tan, David K.Y. Yau, Peng Cheng(2016). Cost of Differential Privacy in Demand Reporting for Smart Grid Economic Dispatch, Advanced Digital Sciences Center, Illinois at Singapore, Nanyang Technological University, 2016.

[29] S.Ramabhotla, Dr.S.Bayne, Dr.M.Giessselmann(2014). Economic dispatch optimization of micro grid, in island mode.IEEE, Texas Tech University, Lubbock, TX, 79409.

[30] Wenyuan Tang, and Rahul Jain(2016). Dynamic Economic Dispatch Game the Value of Storage, IEEE transaction on smart grid, VOL. 7, NO. 5.

[31] Q.Zhong, S. Xue1, Z.Wang, J. Duan, M. Zeng, Ge Zhang, (2013). Environmental and Economic Dispatch Model for Smart Microgrid Based on Shuffled Frog Leap Algorithm Optimized by Random Nelder Mead", Beijing 100101 P. R. China.

[32] Niamh O'Connell, Pierre Pinson, Henrik Madsen, and Mark O'Malley, Economic Dispatch of Demand Response Balancing through Asymmetric Block Offers, IEEE.

[33] A. Lal, R. Kumar and U.Mehta(2014). Energy Dispatch Fuzzy Model in Hybrid Power System, International Energy Journal 14, pp.133-142.

[34] A. C. Luna, N. L. Diaz, F. Andrade, Moises Graells, J. M. Guerrero, and J. C. Vasquez(2015). Economic power dispatch of distributed generators in a grid-connected microgrid," in Proc. ECCE-ASIA.

[35] S.Jagdale, K.Deshmukh, A.Patil, H .Sonawane(2016). Production of electric city by fast moving vehecles, specially trains, Volume-4, Issue-11.

[36] Zhenyu Zhou, Changhao Sun, Ruifeng Shi, Zheng Chang, Sheng Zhou, and Yang Li(2017). Robust Energy Scheduling in Vehicle-to-Grid Networks, IEEE Network.

[37] J. Cao1, M. Yu1 and L. J. Tung(2014). Consensus-based distributed control for economic dispatch problem with comprehensive constraints in a smart grid, Department of Electrical and Computer Engineering, Florida State University.

[38] A.S.Nair, P.Ranganathan, H.Salehfar, N.Kaabouch(2017). Uncertainty Quantification of Wind Penetration and Integration into Smart Grid, Department of Electrical Engineering \& Mines University of North Dakota. 
[39] D.Dauer, P.Karaenke, C.Weinhardt(2015). Load Balancing in the Smart Grid, Thirty Sixth International Conference on Information Systems, Fort Worth , Germeny.

[40] Dayong Ye, Minjie Zhang, Danny Sutanto(2014). Decentralised Dispatch of Distributed Energy Resources in Smart Grids via Multi-Agent Coalition Formation, Elsevier Ltd.

[41] Kumar Deb Nath, U(2015). Electric vehicles in Smart Grids, Performance considerations. Retrieved from http://ro.ecu.edu.au/theses/ 1631.

[42] M. Keerthi, T. Purnachandar Rao(2015). Optimal Allocation of Wind Power DG in Power Systems, International Research Journal of Engineering and Technology (IRJET), Volume: 02, Issue: 05.

[43] Rob Kool(2011). Load Management with Demand-Side Management, an overview, Chair IA DSM/EGRD, IEA Demand Side Management, July 6.

[44] R. Mathi and S. Jayalalitha(2016). Clonal Algorithm for Emission Constrained Economic Dispatch Problem in Thermal Power Plants, ARPN Journal of Engineering and Applied Sciences, VOL 11, NO.15, ISSN 1819-6608.

[45] Eisa Bashier M. Tayeb, A. Taifour Ali, Ahmed A. Emam, (2013). Electrical Energy Management and Load Forecasting in a Smart Grid, International Journal of Engineering Inventions e-ISSN: 2278-7461, p-ISSN: 2319-6491 Volume 2, Issue 6, PP: 98-101.

[46] R. H. Liang and J. H. Liao(2007). A Fuzzy-Optimization Approach for Generation Scheduling With Wind and Solar Energy Systems," in IEEE Transactions on Power Systems, vol. 22, no. 4, pp. 1665-1674.

[47] R.Mudumbai, S.Dasgupta, and B.B. Cho(2011). Distributed control for optimal economic dispatch of power generators: the heterogenous case, 50th IEEE Conference on Decision and Control and European Control Conference (CDC-ECC) Orlando, FL, USA ,December 12-15, .

[48] N.O'Connell, P.Pinson, H.Madsen, and M. O'Malley(2013). Economic Dispatch of Demand Response Balancing Through Asymmetric Block Offers, IEEE transaction on power system.

[49] Li Xin, Liang Tian,(2014). Multi-objective optimization of dynamic load balance on smart grid based on economic dispatch, Shandong Agriculture and Engineering University, Jinan City, Shandong Province, China, 250100, 1.

[50] B. Venkatesh, P. Yu, D. Choling and H. B. Gooi(2009). Fuzzy milp unit commitment incorporating wind generators, 2009 IEEE Power \& Energy Society General Meeting, Calgary, AB, pp. 1-1.

[51] Y. Yang(2017). Practical Robust Optimization Method for Unit Commitment of a System with Integrated Wind Resource, Mathematical Problems in Engineering.
[52] Y. Tan et al.(2015). Microgrid stochastic economic load dispatch based on two-point estimate method and improved particle swam optimization, International Transactions on Electrical Energy Systems 25, no. 10 , 2144-2164.

[53] J. Qin and R. Rajagopal(2013). Dynamic programming solution to distributed storage operation and design, $\mathrm{n}$ Proc. IEEE Power Energy Soc. Gen.Meeting (PES), Vancouver, BC, Canada, pp. 1-5.

[54] E. Yao, V. W. S. Wong, and R. Schober(2016). Robust Frequency Regulation Capacity Scheduling Algorithm for Electric Vehicles, IEEE Trans. Smart Grid, vol. 7, no. 2, pp. $1-14$.

[55] S. Maharjan et al.(2013). Dependable Demand Response Management in the Smart Grid, A Stackelberg Game Approach, IEEE Trans. Smart Grid., vol. 4, no. 1, pp. 120-32.

[56] M. Fan, V. Vittal, G. T. Heydt and R. Ayyanar (2013 ). Probabilistic Power Flow Analysis With Generation Dispatch Including Photovoltaic Resources, IEEE Transactions on Power Systems, vol. 28, no. 2, pp. 1797 1805

[57] J.M. Grosso(2014). On Model Predictive Control for Economic and Robust Operation of Generalised Flowbased Networks, PhD thesis, UPC, Barcelona.

[58] W. Liu, J. Qi, X. Chen, and P. H. Christofides(2010). Supervisory Predictive Control of an Integrated Wind/Solar Energy Generation and Water Desalination System, In Proceedings of the 9th International Symposium on Dynamics and Control of Process Systems, Leuven, Belgium.

[59] A. Mandal(2016). Privacy preserving consensus-based economic dispatch in smart grid systems," in International Conference on Future Network Systems and Security, vol. CCIS 670. Springer, pp. 98-110.

[60] Anurag Gupta, K. K. Swarnkar, K.Wadhwani(2012). CombineEconomic Emission Dispatch Problem Using Particle Swarm Optimization, International Journal of Computer Applications (0975-8887), Vol.49- No.6.

[61] H. Nunna and S. Doolla(2013). Multiagent-based distributed-energy-resource management for intelligent microgrids, IEEE Transaction on Industrial Electronics, 60(4):1678-1687,.

[62] A. Selvakumar and K. Thanushkodi(2007). A new particle swarm optimization solution to nonconvex economic dispatch problems, IEEE Transaction on Power Systems, 22(1):42-51.

[63] Á. Lorca and X. A. Sun(2015). Adaptive Robust Optimization With Dynamic Uncertainty Sets for MultiPeriod Economic Dispatch Under Significant Wind, IEEE Transactions on Power Systems, vol. 30, no. 4, pp. 1702-1713.

[64] Warsono, D. J. King, C. S. Ozveren and D. A. Bradley(2007). Economic Load Dispatch Optimization 


\section{International Journal of Engineering Applied Sciences and Technology, 2019 \\ Vol. 3, Issue 11, ISSN No. 2455-2143, Pages 71-77 \\ Published Online March 2019 in IJEAST (http://www.ijeast.com)}

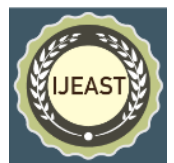

of Renewable Energy in Power System Using Genetic Algorithm, 2007 IEEE Lausanne Power Tech, Lausanne, pp. 2174-2179.

[65] G. Strbac(2008). Demand side management: Benefits and challenges, Energy Policy, vol. 36, pp. 4419-4426.

[66] C. D. Jonghe, B. Hobbs, and R. Belmans(2012). Optimal generation mix with short-term demand response and wind penetration,IEEE Transaction power system, vol. 27, no. 2, pp. 830-839.

[67] S. H. Madaeni and R. Sioshansi(2012). The impacts of stochastic programming and demand response on wind integration, Energy system, vol. 4,pp. 109-124.

[68] S. Borenstein(2005). The long-run efficiency of realtime electricity pricing, Energy journal, vol. 26, no. 3, pp. 93-116.

[69] C. Chen(2008). Economic dispatch using simplified personal best oriented particle swarm optimizer, Electric Utility Deregulation and Restructuring and Power Technologies, DRPT 2008. Third International Conference on. IEEE, 2008, pp. 572-576.

[70] O. Corradi, H. Ochsenfeld, H. Madsen, and P. Pinson(2013). Controlling electricity consumption by forecasting its response to varying prices, I E E E Transaction Power system, vol. 28, no. 1, pp. 421-429.

[71] T. Hovgaard, L. Larsen, J. Jørgensen, and S. Boyd(2013). Nonconvex model predictive control for commercial refrigeration,International journal of control, vol. 86, no. 8, pp. 1349-1366.

[72] S. E. Shafiei, H. Rasmussen, and J. Stoustup(2013). Modeling supermarket refrigeration systems for demand-side management, Energies, vol. 6, pp. 900920.

[73] Cai Qiuna, Wen Fushuan, Xue Yusheng, et al(2012). An SCUC-based optimization approach for power system dispatching with plug-in hybrid electric vehicle, Automation of Electric Power Systems 36(1), 38-46.

[74] Lemay, M., Nelli, R., Gross, G., and Gunter, C. A(2008). An Integrated Architecture for Demand Response Communications and Control, Hawaii International Conference on System Sciences,Proceedings of the 41st Annual, pp. 174-174

[75] Varaiya, P. P., Wu, F. F., and Bialek, J. W,(2011). Smart Operation of Smart Grid: Risk-Limiting Dispatch, Proceedings of the IEEE (99:1), pp. 40-57.

[76] P. Scott and W. Thi'ebaux(2015). Distributed multiperiod optimal power flow for demand response in microgrids, In Proc. of e-Energy, pages 17-26.

[77] Saber AY, Venayagamoorthy GK(2012). Resource scheduling under uncertainty in a smart grid with renewables and plug-in vehicles, IEEE Syst J 6(1):103109.

[78] Abido. M,Anichedpareto(2003). A niched Pareto Genetic algorithm for multi objective environmental/economic dispatch, International Journal of Electrical Power and Energy Systems Vol.25, Issue:2, pp. 97-105.

[79] Hemamalini S. and Simon S.P(2010). Dynamic economic dispatch using Maclaurin series based Lagrangian method, International Journal on Energy Conversion and Management. Vol: 51, Issue: 11, pp. 2212-2219.

[80] Cheng C.P., Liu C.W., Liu C.C(2002). Unit Commitment by Annealing-Genetic algorithm, International Journal on Electrical Power and Energy Systems. Vol: 24, Issue: 2, pp. 149-158.

[81] Jichun Liu, Jie Li(2015). A Bi-Level Energy-Saving Dispatch in Smart Grid Considering Interaction between Generation and Load, Smart Grid, IEEE Transactions on Smart Grid. Vol: 6, Issue: 3, pp. 1443-1452.

[82] CHEN Gonggui, LI Zhihuan, CHEN Jinfu(2009). SFL Algorithm Based Dynamic Optimal PowerFlow in Wind Power Integrated System, Automation of Electric Power Systems, 33, No. 4, 25-30

[83] Dong Jun, CHEN Xiao-liang, ZHANG Jing(2009). Study of power grid dispatching models with consideration of distributed generators, East China Electric Power, 37, No. 5, 723-726.

[84] G. Binetti, A. Davoudi, F. K. Lewis, D. Naso, and B. Turchiano, (2014). Distributed consensus-based economic dispatch with transmission losses, IEEE Trans. Power Syst., vol. 29, no. 4, pp. 1711-1720.

[85] H. Liang, B. J. Choi, A. Abdrabou, W. Zhuang, and X. Shen(2012). Decentralized economic dispatch in microgrids via heterogeneous wireless networks, IEEE J. Sel. Areas Commun., vol. 30, no. 6, pp. 1061-1074. 